\title{
BILIARY TRANSPORT AND HEPATIC STORAGE OF SULFO- BROMOPHTHALEIN SODIUM IN THE UNANESTHETIZED DOG, IN NORMAL MAN, AND IN PATIENTS WITH HEPATIC DISEASE *
}

\author{
By HENRY O. WHEELER, $†$ JAY I. MELTZER AND STANLEY E. BRADLEY \\ (From the Department of Medicine, Columbia University College of Physicians and Surgeons, \\ and the Presbyterian Hospital, New York, N. Y.)
}

(Submitted for publication January 11, 1960; accepted March 31, 1960)

Since its introduction in 1924 by Rosenthal and White (1), the dye sulfobromophthalein sodium (BSP) has proven useful not only for clinical purposes but also for physiological investigations of splanchnic vascular perfusion, hepatocellular function, and biliary secretory mechanisms. It has been shown that removal of BSP from the plasma by the liver depends upon two distinct processes: 1) accumulation of dye in hepatic cells and 2) active secretion into the biliary tract.

Hepatocellular accumulation or "storage" of BSP was first suggested by the demonstration of a marked delay between removal from the blood and excretion into the bile after the dye was administered intravenously to dogs $(2,3)$, and a similar mechanism in man was inferred from a study of the hepatic removal of successive doses of BSP (4). The accumulation of a related phthalein dye, fluorescein, in hepatic polygonal cells has actually been visualized in living frog and rat livers by the technique of fluorescence microscopy $(5,6)$. In the case of another phthalein dye, $\mathrm{I}^{131}$-labeled rose bengal, an accumulation or "storage phase" is apparent in the curves obtained by external counting over the liver after intravenous injection (7), and high concentration within liver cells has been confirmed by radioautography (8). Although it has been suggested that accumulation of BSP may proceed until there is complete "saturation" of intrahepatic storage sites $(4,9)$, more recent evidence indicates that the process tends toward an equilibrium state in which the quantity (and hence the concentration) of BSP in the liver is directly proportional to the concentration of dye in the surrounding plasma (10). It has therefore been possible to define a BSP "relative

* This investigation was supported by a grant from the Department of the Army (Contract DA-49-007-MD205).

† Markle Scholar in Medical Science. storage capacity" ( $\mathrm{S}$ ) as the number of milligrams of BSP stored in the liver per milligram per 100 $\mathrm{ml}$ of plasma concentration. The value of $\mathrm{S}$ can be estimated by comparison of the rates of movement of BSP into the liver associated with different rates of change of plasma concentration (10). The method of calculation is described below.

The high concentrations of BSP observed in the bile (2) indicate that the ultimate excretion of this dye undoubtedly depends upon an active transport mechanism. There is convincing indirect evidence in the dog $(9-11)$, in the rabbit $(12,13)$, and in man $(14,15)$ that the secretion of BSP into the bile is limited by a definite maximal rate, analogous to the transport maximum, or "Tm," which is demonstrable for many substances secreted by the renal tubules. For understandable technical reasons the BSP transport maximum has not, until the present, been measured directly by bile collection. Moreover, because of the nature of the BSP storage process, the rate of biliary secretion cannot be equated to the rate of hepatic removal of BSP from the plasma unless the plasma level is absolutely constant. An indirect estimation of the BSP transport maximum is possible, nevertheless, by analysis of the data obtained during determination of relative storage capacity (10).

With a method at hand for the quantitation of $\mathrm{BSP}$ relative storage capacity and transport maximum, it has been possible to study hepatocellular function and biliary secretion in the unanesthetized dog and to evaluate the effect of hepatic disease on these processes in man. The results are presented in this paper.

\section{THEORETICAL CONSIDERATIONS}

The hepatic removal rate of BSP at any instant must be equal to the sum of the biliary excretion rate plus the rate of accumulation (or minus the rate of deple- 
tion) of BSP in hepatic parenchymal storage. The biliary excretion rate, under conditions where the secretory transport mechanism is saturated, is equal by definition to $\mathrm{Tm}$. If the number of milligrams of BSP stored in the liver cells per milligram per $100 \mathrm{ml}$ of plasma BSP concentration is defined by the relative storage capacity, $\mathrm{S}$, then the rate of accumulation (or depletion) of stored BSP will be equal to the product of $S$ times the rate of change of plasma concentration $(\Delta \mathrm{p} / \Delta \mathrm{t})$. Thus hepatic removal rate, $\mathrm{R}$, is a function of both the secretory and storage processes:

$$
\mathrm{R}=\mathrm{Tm}+\mathrm{S} \cdot(\Delta \mathrm{p} / \Delta \mathrm{t})
$$

where $\quad \mathrm{R}=$ hepatic removal rate, milligrams per minute ;

$\mathrm{Tm}=$ secretory transport maximum, milligrams per minute;

$\mathrm{S}=$ relative storage capacity, milligrams per milligram per $100 \mathrm{ml}$;

$\Delta \mathrm{p} / \Delta \mathrm{t}=$ rate of change of plasma concentration, milligrams per $100 \mathrm{ml}$ per minute.

The value of $\Delta p / \Delta t$ can be determined by measurement of BSP concentration in serial plasma samples, and, since extrahepatic removal is small (10), " $R$ " can be calculated by the equation $\mathrm{R}=\mathrm{I}-\mathrm{PV} \cdot(\Delta \mathrm{p} / \Delta \mathrm{t}$ ) (where $\mathrm{I}=$ infusion rate in milligrams per minute and $\mathrm{PV}=$ plasma volume in hundreds of milliliters). Thus, Equation 1 contains two unknowns, $\mathrm{Tm}$ and $\mathrm{S}$. Solution is possible by substitution of two sets of values for $R$ and $\Delta \mathrm{p} / \Delta \mathrm{t}$ obtained during two different rates of BSP infusion. In actual practice three different rates of infusion were employed in the present studies in order to test the linearity of the relationship between $\mathrm{R}$ and $\Delta \mathrm{p} / \Delta \mathrm{t}$ which is implied in Equation 1 . When three determinations are available, the best solution is obtained by plotting the three values for $\mathrm{R}$ (ordinate) against the corresponding values of $\Delta \mathrm{p} / \Delta \mathrm{t}$ (abscissa). In most instances the relationship between $\mathrm{R}$ and $\Delta \mathrm{p} / \Delta \mathrm{t}$ proves to be approximately linear as predicted from Equation 1, and the best straight line through the three points is determined by the method of least squares (16). The $\mathrm{Tm}$ is then equal to the value of $\mathrm{R}$ for which $\Delta \mathrm{p} / \Delta \mathrm{t}=0$, and $\mathrm{S}$ is equal to the slope of the least squares line.

It should be noted that the relative storage capacity, $S$, as defined, has the dimensions of a volume (in hundreds of milliliters). In view of the relationship between BSP storage and plasma concentration (10) the hepatic storage compartment can be considered, in a sense, as an extension of the plasma volume. When regarded in this way the present method is quite similar to one of the techniques proposed by Lewis (12) for the estimation of BSP " $\mathrm{L}_{\mathrm{m}}$ " and "BSP fluid compartment."

\section{METHODS}

\section{A. Procedure in dogs}

Fifteen studies were conducted on 6 trained adult mongrel dogs, weighing between 16 and $30 \mathrm{~kg}$, which had previously undergone splenectomy, cholecystectomy, and installation of a Thomas duodenal fistula apparatus (17). At the time of an experiment the fistula was opened to permit visualization of the Ampulla of Vater through which a no. 5 or no. 6 Fr. olive-tipped ureteral catheter was inserted and advanced about 5 or $6 \mathrm{~cm}$ into the common bile duct. The dog was then placed upright in a sling. Bile was collected by gravity or, when it was particularly viscous, by gentle aspiration with a tuberculin syringe. Venous blood samples were collected in heparinized tubes. After obtaining blood and bile samples for analytical blanks, BSP in 5 per cent dextrose was infused intravenously for 1 hour at a constant rate of 0.4 to $0.5 \mathrm{mg}$ per minute per $\mathrm{kg}$ (roughly twice the anticipated BSP "Tm") using a Bowman pump. During the last 30 minutes of this infusion 4 blood samples were collected at 10 minute intervals. During the second and third hours this procedure was repeated at BSP infusion rates of approximately 0.2 to 0.3 and 0.5 to 0.6 times the initial rate, respectively. In 6 studies a rapid $\mathrm{BSP}$ infusion (1 to 1.5 times the initial rate) was administered during the fourth hour in order to achieve a very high plasma level. Bile was obtained continuously and collected in successive separate graduated tubes at intervals of 10 to 15 minutes. Plasma volume was measured during the course of each study using $\mathrm{I}^{\text {131 }}$-labeled human serum albumin. The activity of a plasma sample obtained 10 minutes after tracer injection was compared with that of an aliquot of the injectate diluted to known volume with isotope-free "carrier" plasma to avoid adsorption of tracer to glass. At the end of each study the rates of delivery of the Bowman pump were calibrated.

\section{B. Procedure in man}

Studies were conducted on 4 normal male volunteers, on 15 hospital patients without liver disease, and on 15 patients with various hepatic disorders. A second study was conducted on 2 of the normal volunteers 3.5 months after the first determination. The procedure was begun about an hour after a fat-free breakfast. After obtaining an initial blood sample BSP was infused for 1 hour at a constant rate of approximately $0.3 \mathrm{mg}$ per minute per kg. Four venous blood samples were drawn at 10 minute intervals during the last 30 minutes of this infusion. This procedure was repeated at infusion rates usually 0.3 and 0.6 times the initial rate during the second and third hours, respectively. In the presence of liver disease the same procedure was followed, but all infusion rates were scaled down to 25 to 50 per cent of those employed in normal subjects. A rapid estimation of the BSP concentration in the first two blood specimens was carried out so that, if necessary, the subsequent infusion rates could be adjusted to avoid BSP concentrations outside the range of 2.5 to $15 \mathrm{mg}$ per $100 \mathrm{ml}$. Plasma volume was measured during the first hour in all subjects using $I^{131}$-labeled human serum albumin.

\section{Analytical methods}

Plasma. One $\mathrm{ml}$ of each plasma sample was diluted by the addition of $10 \mathrm{ml}$ of normal saline and $0.2 \mathrm{ml}$ of 
20 per cent potassium hydroxide. The optical density was determined in a Beckman DU spectrophotometer at $580 \mathrm{~m} \mu$. The optical density of a similarly treated plasma "blank" (obtained before the infusion of BSP) was subtracted. Standard curves for this determination were prepared by the addition of known amounts of BSP to canine plasma and to both normal and icteric human plasma. It was found that accurate results could be obtained in icteric plasma provided that 15 minutes were allowed for complete color change of bilirubin after alkalinization and provided the appropriate blank was subtracted.

Bile. The determination of BSP concentration in bile was complicated by the finding that the spectrophotometric recovery of BSP added to bile was often significantly reduced when the bile was diluted in the range of 200 - to 1,000 -fold. The reason for this phenomenon was not apparent, but it was found empirically that accurate measurement of BSP could always be obtained if the final dilution of bile was less than 200-fold. Since the BSP concentrations encountered in dog bile necessitated a higher dilution, this problem was circumvented by the addition of "blank" bile to the dilute bile specimens. A pooled control bile sample, obtained before BSP infusion, served as the source of the "blank" bile.

All bile samples were first diluted 100 times with distilled water. One $\mathrm{ml}$ of the diluted sample was then mixed with $1 \mathrm{ml}$ of a fivefold dilution of the "blank" bile, $20 \mathrm{ml}$ of water, and $0.4 \mathrm{ml}$ of 20 per cent potassium hydroxide and the optical density determined at $580 \mathrm{~m} \mu$. The optical density of a similarly treated control bile was subtracted.

Infusion mixture. Concentration of BSP in the infusion mixture was determined at $580 \mathrm{~m} \mu$ after appropriate aqueous dilution and addition of alkali.

\section{Calculation of $T m$ and $S$}

The values of plasma BSP concentration were plotted on a linear scale against time. The rate of change of $\mathrm{BSP}$ concentration $(\Delta \mathrm{p} / \Delta \mathrm{t})$ during the last 30 minutes of each infusion period was calculated by application of the method of least squares (16) to the 4 points obtained during that time, although in most instances a reasonably straight line through the 4 points could have been fitted by eye. A value of hepatic removal rate was determined for each infusion period, and $\mathrm{Tm}$ and $\mathrm{S}$ were calculated as described under "Theoretical Considerations."

\section{RESULTS}

\section{A. Dogs}

$T m$ and $S$. During the latter half of each period of constant BSP infusion the plasma BSP concentration ( $\mathrm{P}$ ) changed in an approximately linear fashion with respect to time (Figure 1). Thus a constant hepatic BSP removal rate was achieved during each of the three constant infusions. When the three values of $R$ were plotted

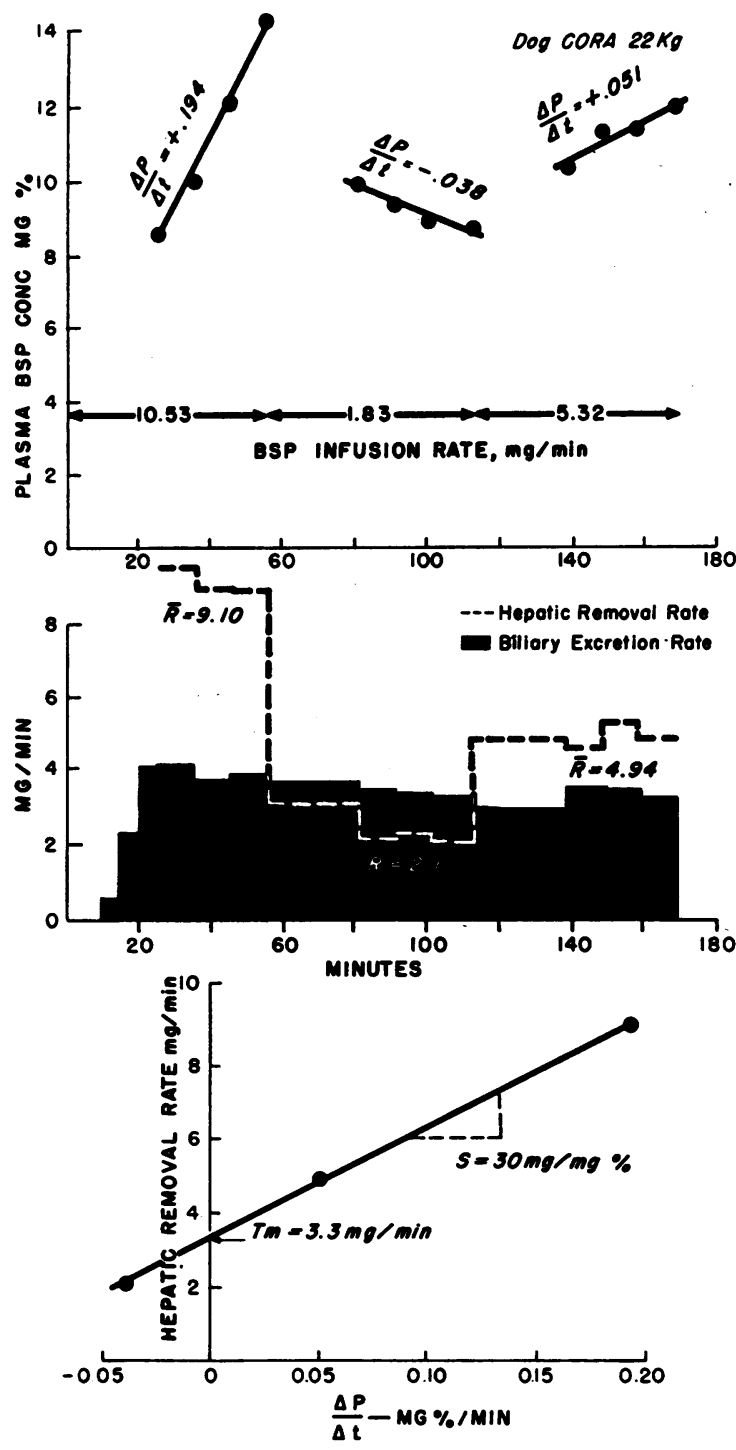

Fig. 1. Estimation of BSP TM AND $S$ in the DoG. Constant infusions of BSP were administered at the three rates indicated. Plasma concentration changed in linear fashion with respect to time during the latter half of each infusion period. Biliary BSP excretory rate achieved a maximal value of $4 \mathrm{mg}$ per minute within 30 minutes of starting BSP and was thereafter independent of plasma concentration, although it tended to diminish gradually as the study progressed. The hepatic BSP removal rate was greater than the excretory rate during periods of increasing plasma concentration, indicating accumulation of BSP in the liver. When plasma concentration was falling, removal rate was less than excretory rate indicating net depletion of stored BSP. The relationship between $\Delta \mathrm{p} / \Delta \mathrm{t}$ and removal rate (R) shown below is consistent with the relationship : $R=$ $\mathrm{Tm}+\mathrm{S} \cdot(\Delta \mathrm{p} / \Delta \mathrm{t})$. Tm and $\mathrm{S}$ are calculated from the intercept $(\Delta \mathrm{p} / \Delta \mathrm{t}=0)$ and the slope of this line, respectively. 
against the corresponding rates of change of plasma concentration $(\Delta \mathrm{p} / \Delta \mathrm{t})$ there was usually a linear relationship between these variables as in the example shown in Figure 1. Owing to the difficulty of maintaining a steady state, some deviation of this relationship from linearity occurred in several experiments, but in only one study (not included in the 15) was this deviation so pronounced that it would have been unreasonable to construct a straight "least squares" line through the three points.

The values of $\mathrm{Tm}$ and $\mathrm{S}$ are shown in Table I. Average values for individual dogs were computed on the basis of five studies on one dog and two studies on each of the others. In accordance with customary procedure these were arbitrarily adjusted to a body weight of $10 \mathrm{~kg}$, although of course the data were insufficient to test the actual correlation with body size. The mean $\mathrm{Tm}$ for the six dogs was $1.9 \mathrm{mg}$ per minute per $10 \mathrm{~kg}$ (range
1.4 to 3.2 ) and the mean value of $\mathrm{S}$ was $25 \mathrm{mg}$ per $\mathrm{mg}$ per $100 \mathrm{ml}$ per $10 \mathrm{~kg}$ (range 21 to 35 ).

Biliary BSP excretion. Control bile flow was usually between 0.05 to $0.15 \mathrm{ml}$ per minute. Following the onset of BSP infusion there was invariably at least a twofold increase in flow. Thereafter spontaneous fluctuations in flow were commonly observed. The biliary excretion of BSP achieved a maximal rate within about 30 minutes of starting BSP infusion when plasma concentration exceeded $3 \mathrm{mg}$ per $100 \mathrm{ml}$ in all studies. Beyond this point excretory rate was independent of plasma BSP concentration and of hepatic removal rate as shown in Figure 1. Even when excessively high plasma levels (22.4 to $48.3 \mathrm{mg}$ per $100 \mathrm{ml}$ ) were produced at the end of six studies by rapid BSP infusion there was no further increase in excretory rate, so that it was apparent that the maximal capacity for BSP transport had been achieved. The BSP excretory rate, averaged

TABLE I

$B S P$ transport maximum $(T m)$, relative storage capacity $(S)$ and biliary excretion rate in unanesthetized dogs

\begin{tabular}{|c|c|c|c|c|c|c|c|c|}
\hline Dog & Date & $\mathrm{Wt}$ & $\mathrm{Tm}$ & $\underset{\text { Tm }}{\text { Adjusted }}$ & $\mathrm{S}$ & $\underset{\mathrm{S}}{\text { Adjusted }}$ & $\begin{array}{l}\text { BSP ex- } \\
\text { cretion } \\
\text { rate* }\end{array}$ & $\frac{\text { Excretion rate }}{\mathrm{Tm}} \times 100$ \\
\hline \multirow{6}{*}{ Norma } & & $k g$ & $m g / m i n$ & $\begin{array}{l}m g / m i n / \\
10 \mathrm{~kg}\end{array}$ & $m g / m g \%$ & $\begin{array}{c}m g / m g \% / \\
10 \mathrm{~kg}\end{array}$ & $m g / \min$ & \\
\hline & $12 / 18 / 57$ & 17.6 & 4.5 & 2.6 & 53 & 30 & 3.6 & 79 \\
\hline & $1 / 10 / 58$ & 17.6 & 4.4 & 2.5 & 24 & 13 & 3.4 & 78 \\
\hline & $2 / 5 / 58$ & 17.6 & 4.2 & 2.4 & 30 & 17 & 3.1 & 75 \\
\hline & $2 / 26 / 58$ & 17.5 & 3.2 & 1.8 & 44 & 25 & 3.0 & 95 \\
\hline & $10 / 15 / 58$ & 20.9 & 3.4 & 1.6 & 69 & 33 & 3.4 & 99 \\
\hline \multicolumn{2}{|l|}{ Average } & & & 2.2 & & 24 & & \\
\hline \multirow{2}{*}{ Nero } & $2 / 20 / 58$ & 15.9 & 5.3 & 3.3 & 40 & 25 & 3.3 & 62 \\
\hline & $3 / 7 / 58$ & 15.9 & 4.9 & 3.1 & 48 & 30 & 3.9 & 81 \\
\hline \multicolumn{2}{|l|}{ Average } & & & 3.2 & & 27 & & \\
\hline \multirow{2}{*}{ Cora } & $3 / 12 / 58$ & 22.0 & 2.8 & 1.2 & 49 & 22 & 2.5 & 92 \\
\hline & $3 / 27 / 58$ & 22.0 & 3.3 & 1.5 & 30 & 14 & 3.5 & 104 \\
\hline Average & & & & 1.4 & & 18 & & \\
\hline \multirow{2}{*}{ Tosca } & $5 / 12 / 58$ & 19.5 & 4.0 & 2.1 & 67 & 35 & 2.8 & 68 \\
\hline & $5 / 26 / 58$ & 20.4 & 2.3 & 1.1 & 72 & 35 & 2.6 & 113 \\
\hline Average & & & & 1.6 & & 35 & & \\
\hline \multirow{3}{*}{$\begin{array}{l}\text { Isolde } \\
\text { Average }\end{array}$} & $6 / 11 / 58$ & 23.6 & 3.9 & 1.6 & 76 & 32 & 3.6 & 94 \\
\hline & $3 / 13 / 59$ & 30.2 & 4.3 & 1.4 & 56 & 19 & 4.2 & 97 \\
\hline & & & & 1.5 & & 25 & & \\
\hline \multirow{3}{*}{$\begin{array}{l}\text { Dali } \\
\text { Average }\end{array}$} & $8 / 18 / 58$ & 22.7 & 2.8 & 2.8 & 45 & 20 & 2.3 & 84 \\
\hline & $11 / 17 / 58$ & 22.7 & 3.9 & 1.7 & 49 & 22 & 3.6 & 91 \\
\hline & & & & 1.5 & & 21 & & \\
\hline \multicolumn{9}{|c|}{$\begin{array}{l}\text { Mean } \mathrm{Tm} 1.9 \mathrm{mg} / \mathrm{min} / 10 \mathrm{~kg} \text { (range } 1.4 \text { to } 3.2 \text { ) } \\
\text { Mean S } 25 \mathrm{mg} / \mathrm{mg} \% / 10 \mathrm{~kg} \text { (range } 21 \text { to } 35 \text { ) } \\
\text { Excretion rate }\end{array}$} \\
\hline \multicolumn{9}{|c|}{$\frac{\text { Excretion rate }}{T \mathrm{~m}} \times 100:$ Mean $\pm \mathrm{SD} 87.5 \pm 13.4 \%$} \\
\hline
\end{tabular}

* Average BSP excretion rate from time maximum achieved to end of study. 


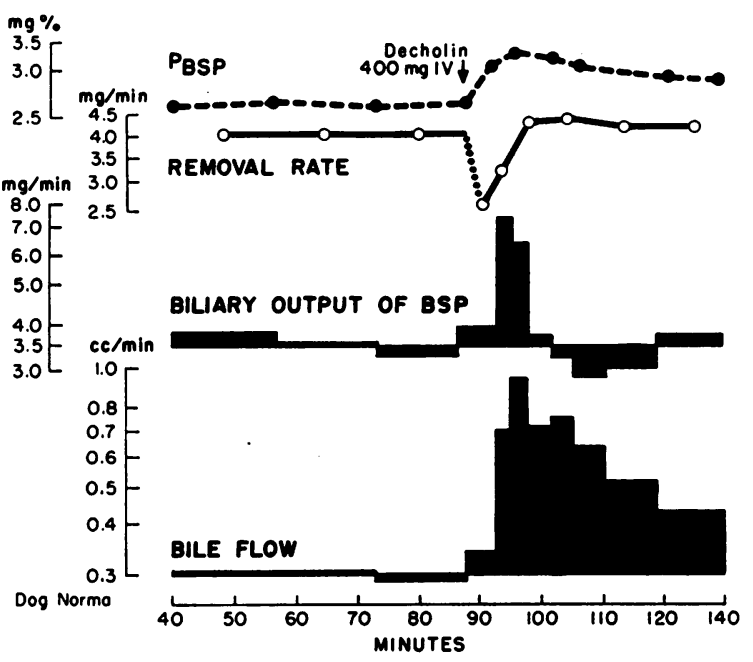

Fig. 2. EFFECT of SODIUM DEHydRocholate (DechoLIN). At time zero a "priming" intravenous dose of 200 $\mathrm{mg}$ of BSP was given and a constant infusion at 4.04 $\mathrm{mg}$ per minute was started. Administration of $400 \mathrm{mg}$ of Decholin at the time indicated resulted in a sudden diminution in hepatic BSP removal rate, shown by the abrupt rise in plasma concentration. Bile flow increased markedly. The apparent increase in BSP excretory rate was attributable to the lag between flow and concentration changes caused by the biliary "dead space" (see text), and was followed by an apparent decrease due to the same cause. On the average, BSP excretory rate was not altered by Decholin (3.75 compared to $3.60 \mathrm{mg}$ per minute), indicating continued transport of BSP from liver cells to bile during the period of reduced hepatic removal rate.

from the time the maximal rate was achieved until the end of the 3 hours of infusion, is shown in Table I. In the last column these figures are compared with the values for estimated BSP Tm. The observed excretory rate was equal, on the average, to $87.5 \pm \mathrm{SD} 13.4$ per cent of the estimated Tm.

The maximal biliary excretory rate was not associated with a constant BSP concentration in bile. The latter varied considerably from study to study (range 700 to $4,210 \mathrm{mg}$ per $100 \mathrm{ml}$ ). It also varied during the course of individual studies as bile flow changed. In one dog, for example, a spontaneous change in bile flow from 0.164 to $0.079 \mathrm{mg}$ per minute was associated with a change in BSP concentration from 1,940 to $4,210 \mathrm{mg}$ per $100 \mathrm{ml}$ without alteration in BSP excretory rate, and similar changes were observed from time to time in all animals.

In many studies, however, there was a definite diminution in the excretory rate over the 2 to 3 hours following the establishment of the maximal rate. As in the example in Figure 1, this change was usually gradual and did not appear to be related to any specific step in the procedure. The overall change amounted to less than 15 per cent in seven studies. There was a 15 to 30 per cent diminution in five studies and a 30 to 40 per cent diminution in three. The average change for 15 studies was -15 per cent.

Effect of sodium dehydrocholate. That the hepatic uptake and biliary excretion of BSP are independent processes was further shown by the
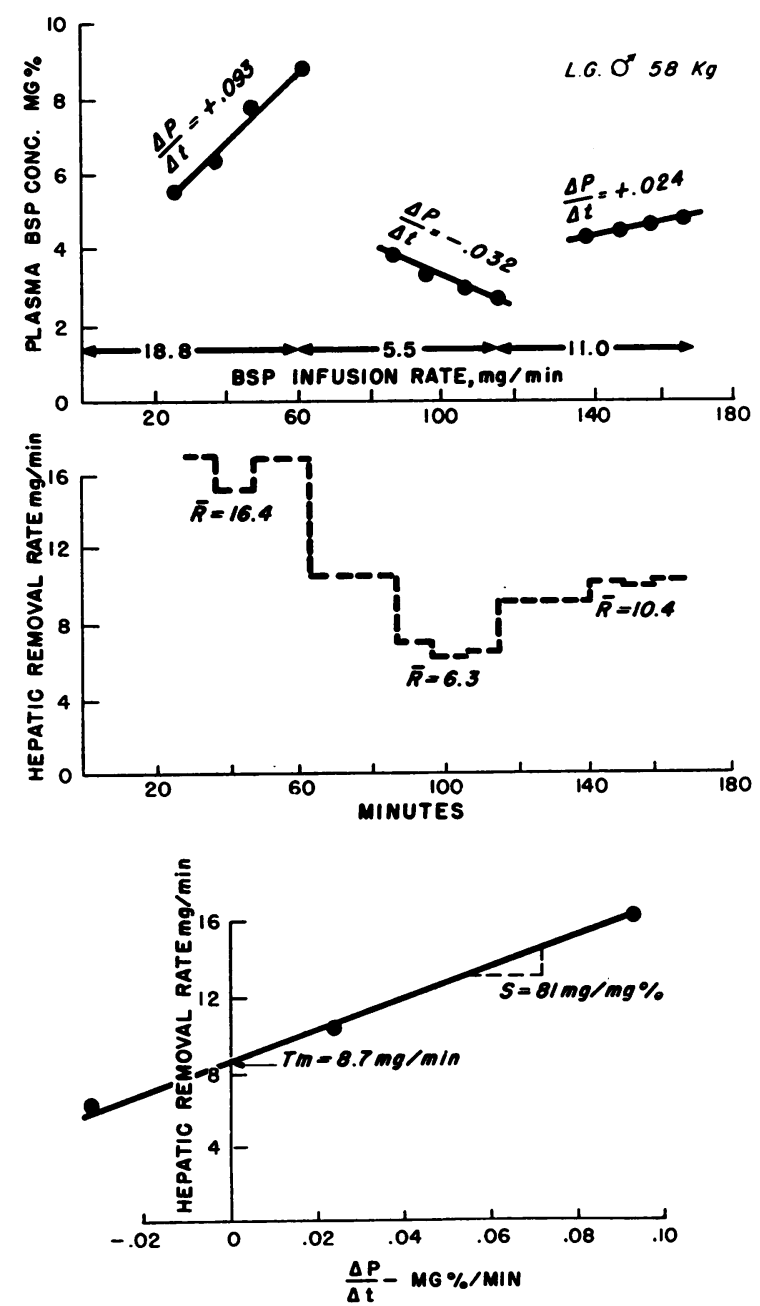

Fig. 3. Estimation of BSP TM AND $S$ IN NORMAL MAN. Except for the actual rates of BSP infusion and the absence of data on biliary excretion, the technique and interpretation are identical with that shown in Figure 1 for the dog. (Note the very rapid removal rate during the period of increasing plasma concentration.) 
effect of sodium dehydrocholate. In two dogs a "priming" intravenous dose of BSP (approximately $13 \mathrm{mg}$ per $\mathrm{kg}$ ) was followed by a constant infusion at a rate approximately equal to the previously estimated BSP Tm. By this means a relatively constant plasma concentration was achieved. After approximately 80 minutes, 400 mg of sodium dehydrocholate (Decholin) was administered intravenously. The response was identical in the two dogs and is illustrated in Figure 2. There was an abrupt diminution in hepatic removal rate (indicated by sudden increase in plasma concentration). This was followed in about 5 minutes by an increased removal rate, and finally, after about 25 minutes, by the restoration of control removal rate and plasma level. The administration of sodium dehydrocholate produced a marked transient increase in bile flow ( 0.30 to
0.98 and 0.36 to $0.80 \mathrm{ml}$ per minute in the two dogs). Corresponding to this increase there was a reciprocal reduction in biliary BSP concentration which, however, was not observed until an additional 2 to $3 \mathrm{ml}$ of the bile had been collected. This volume is somewhat smaller than a previous estimate of about $5 \mathrm{ml}$ for the "dead space" of the canine biliary tract (18), possibly because the common duct and major hepatic ducts were maintained in a collapsed state by continuous aspiration in the present studies. Because of the "dead space" lag between flow and concentration changes, the calculated BSP excretory rate showed an abrupt increase followed by a decrease below the control rate. However, the average BSP excretory rate over the entire period of dehydrocholate effect did not differ significantly from the control excretory rate despite the inhibition of removal of

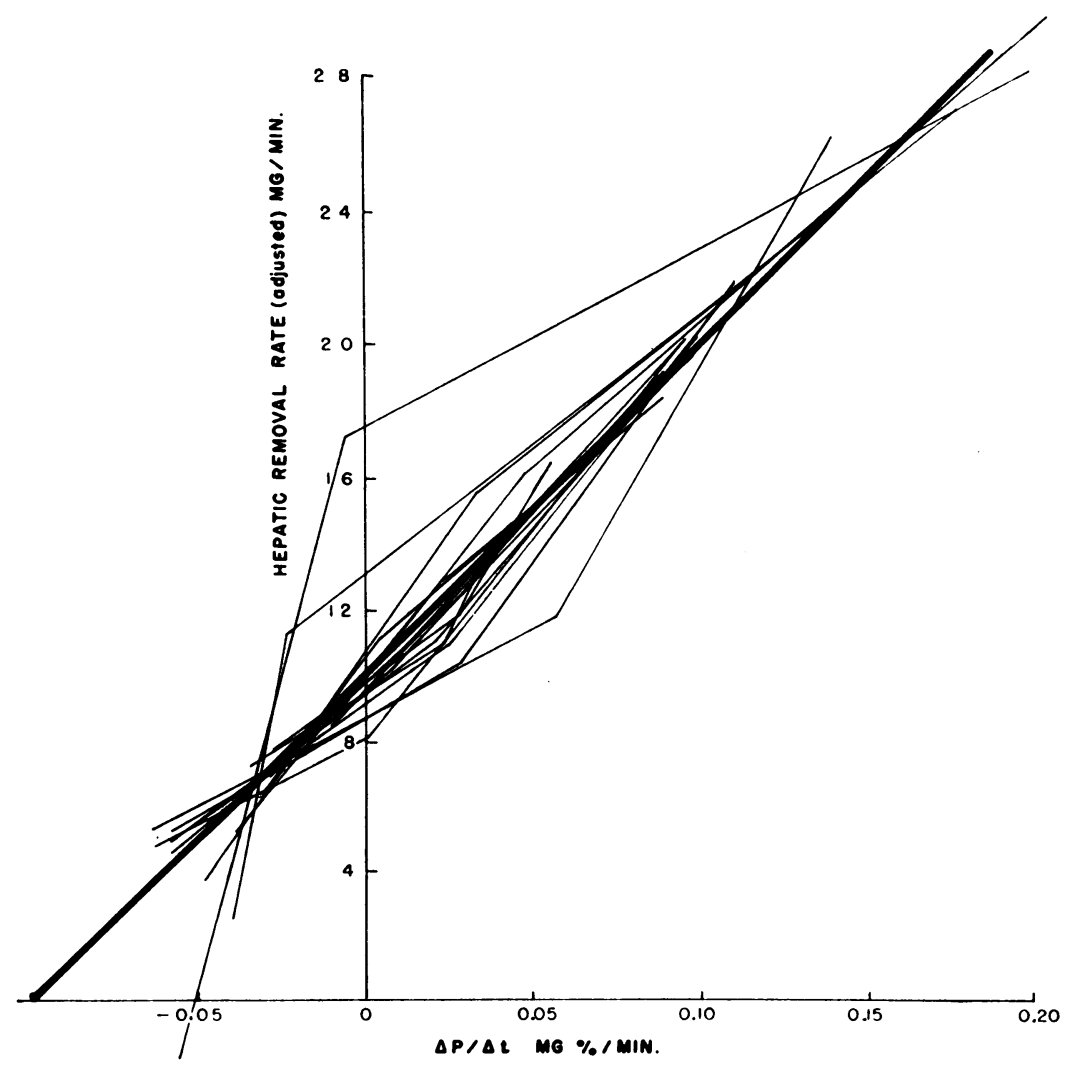

Fig. 4. Relationship Between adjusted BSP Removal RAte ( $\left.R^{\prime}\right)$ AND $\Delta \mathrm{p} / \Delta \mathrm{t}$ IN 19 NORMAL SUBJECTS. Actual values of removal rate have been adjusted (see text) so that the three points $\left(\Delta \mathrm{p} / \Delta t, R^{\prime}\right)$ for each subject fall about the line $\mathrm{R}^{\prime}=10+100 \cdot(\Delta \mathrm{p} / \Delta \mathrm{t})$. In most subjects the relationship between removal rate and rate of change of plasma concentration is close to the postulated straight line. 
TABLE II

BSP transport maximum $(T m)$ and relative storage capacity $(S)$ in normal human subjects

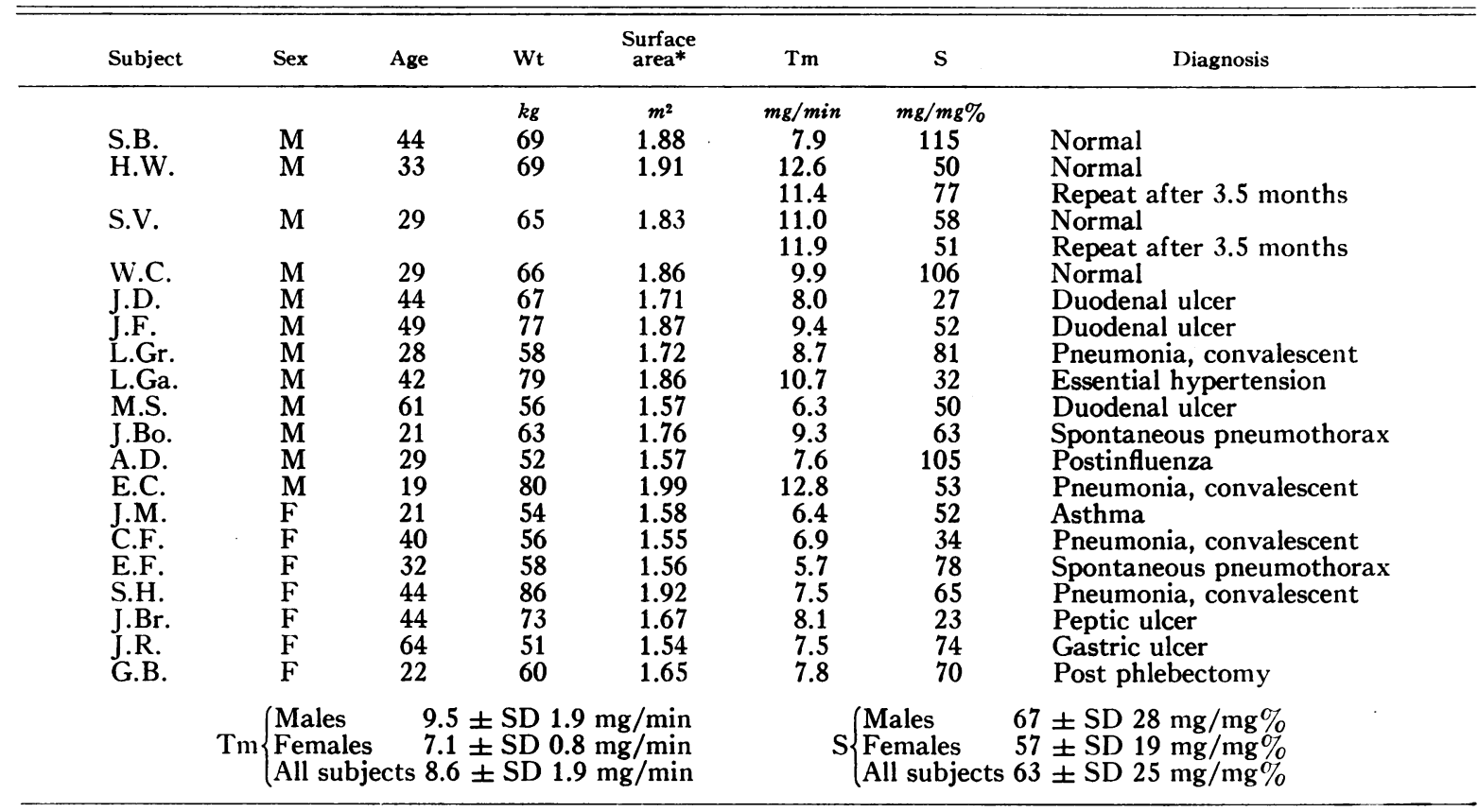

* Surface area estimated from height and weight by nomogram of Boothby and Sandiford (32).

BSP from plasma. In one dog BSP excretory rate following dehydrocholate injection averaged 3.75 compared with a control rate of $3.60 \mathrm{mg}$ per minute, and in the other dog 4.41 compared with $4.27 \mathrm{mg}$ per minute.

Enterohepatic circulation of BSP. When estimations of $\mathrm{Tm}$ and $\mathrm{S}$ are undertaken without bile collection (as in the studies in man which follow), an error might arise if a significant quantity of the excreted BSP were reabsorbed. An investigation of the magnitude of intestinal absorption of this dye was therefore carried out. In two dogs, $600 \mathrm{mg}$ of BSP was administered into the duodenum ( $48 \mathrm{ml}$ of $1,250 \mathrm{mg}$ per $100 \mathrm{ml}$ solution in normal saline given over a 40 minute period). Within 30 minutes after introduction of the dye measurable quantities appeared in the bile. Maximal bile concentration was achieved in 1 hour in one dog $(648 \mathrm{mg}$ per $100 \mathrm{ml})$ and in 2 hours in the other (535 $\mathrm{mg}$ per $100 \mathrm{ml}$ ) and decreased thereafter, reaching levels under $50 \mathrm{mg}$ per $100 \mathrm{ml}$ within 4 hours. There was no increase in bile flow. Of the total administered dose the fraction recovered in bile in the two dogs at the end of 2 hours was 2.6 and 2.3 per cent, and at the end of 3.5 hours 4.0 and 4.7 per cent, respectively.
In another study $340 \mathrm{mg}$ of BSP was dissolved in $15 \mathrm{ml}$ of dog bile and administered into the duodenum. Only 1.4 per cent was recovered in the bile excreted over the next 4 hours. These observations are similar to those of Lorber and associates (19) in the anesthetized dog, and indicate a very limited interestinal absorption of BSP. Reabsorption of the BSP conjugates normally excreted in the bile may be even more limited. When bile (containing $350 \mathrm{mg}$ of $\mathrm{BSP}$ ) was collected from a dog receiving an intravenous $\mathrm{BSP}$ infusion and administered into the duodenum of another dog, no BSP was detectable in the bile excreted by the latter animal over the next 3 hours.

\section{B. Normal man}

As in the dog, linear rates of change of plasma BSP concentration were observed during the latter half of each infusion period (Figure 3 ). The values of $\mathrm{Tm}$ and $\mathrm{S}$ were calculated as described under "Theoretical Considerations" and as illustrated in Figure 3. The relationship between $\mathrm{R}$ and $\Delta \mathrm{p} / \Delta \mathrm{t}$ proved to be approximately linear in most instances. In order to illustrate 
this relationship on a single composite graph (Figure 4 ), the three values of $R$ in each subject were subjected to the operation $R^{\prime}=R \cdot(100 / S)$ $+[10-\mathrm{Tm} \cdot(100 / \mathrm{S})]$, so that the three points $\left(\Delta \mathrm{p} / \Delta \mathrm{t}, \mathrm{R}^{\prime}\right)$ fell about the least squares line $\mathrm{R}^{\prime}=$ $10+100 \cdot(\Delta \mathrm{p} / \Delta \mathrm{t})$. This operation does not disturb the relative positions of the three points, and it can be seen from Figure 4 that the actual relationship between $R$ and $\Delta p / \Delta t$ adhered rather closely to the postulated straight line in most subjects. Deviations from linearity appeared to be entirely random and can probably be attributed to methodological errors or failure to maintain a steady state for 3 hours.

In four normal males the average Tm was 10.3 $\mathrm{mg}$ per minute and $\mathrm{S}$ was $85 \mathrm{mg}$ per $\mathrm{mg}$ per 100 ml. In eight hospital "normal" males (without liver disease) the average $\mathrm{Tm}$ was $9.1 \mathrm{mg}$ per minute and $\mathrm{S}$ was $58 \mathrm{mg}$ per $\mathrm{mg}$ per $100 \mathrm{ml}$. The mean for both groups was $\mathrm{Tm}=9.5 \pm \mathrm{SD} 1.9$ $\mathrm{mg}$ per minute and $\mathrm{S}=67 \pm \mathrm{SD} 28 \mathrm{mg}$ per $\mathrm{mg}$ per $100 \mathrm{ml}$. In hospital "normal" females Tm was $7.1 \pm \mathrm{SD} 0.8 \mathrm{mg}$ per minute and $\mathrm{S}=57 \pm$ SD $19 \mathrm{mg}$ per $\mathrm{mg}$ per $100 \mathrm{ml}$. The individual results are shown in Table II and in Figure 5. In men but not in women there was a positive correlation between $T m$ and body weight $(R=$ $0.66, \mathrm{p}<0.05)$ and between $\mathrm{Tm}$ and surface area $(\mathrm{R}=0.82, \mathrm{p}<0.01)$. No correlation was apparent between $\mathrm{S}$ and weight or between $\mathrm{S}$ and surface area in either sex. In view of the limited number of subjects, no definite conclusion can be drawn regarding the relationship between various indices of body size and the values of $\mathrm{Tm}$ and $\mathrm{S}$, and therefore no empirical correction for weight or surface area was applied in man.

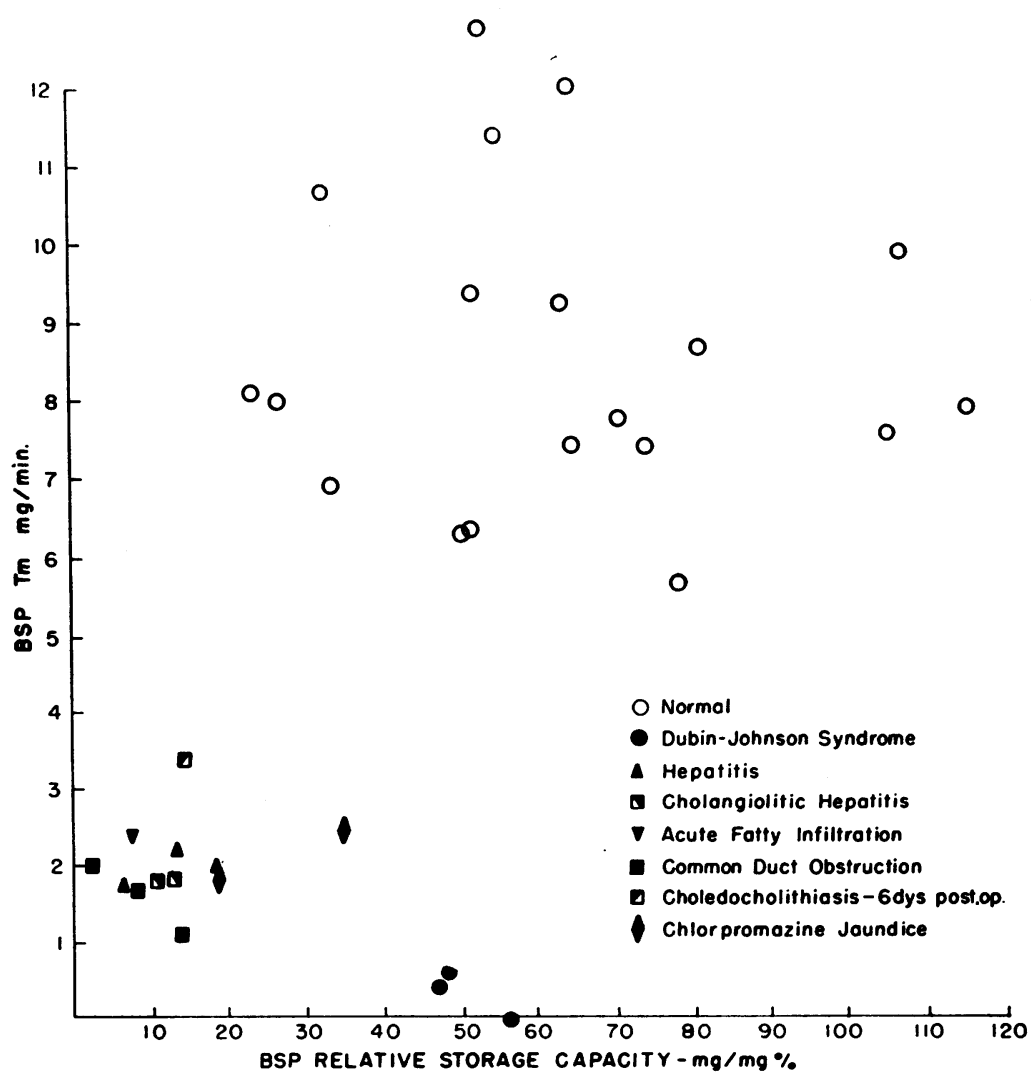

Fig. 5. TM AND S IN NORMal human subjects and in patients with HEPATIC DISORDERS. The marked normal variation in relative storage capacity is apparent from this figure. In patients with obstructive disease as well as in those with hepatocellular disease both $\mathrm{Tm}$ and $\mathrm{S}$ were depressed. The lowest values of $\mathrm{Tm}$, however, occurred in three patients with Dubin-Johnson syndrome whose capacity to store BSP was well within the normal range. 
TABLE III

BSP transport maximum (Tm) and relative storage capacity $(S)$ in patients with hepatic disorders

\begin{tabular}{|c|c|c|c|c|c|c|c|}
\hline Subject & Sex & Age & Wt & $\begin{array}{c}\text { Surface } \\
\text { Area* }\end{array}$ & $\mathrm{Tm}$ & S & Diagnosis \\
\hline & & & $\mathrm{kg}$ & $m^{2}$ & $m g / \min$ & $m g / m g \%$ & \\
\hline J.W. & $\mathrm{F}$ & 18 & 52 & 1.51 & 1.8 & 7 & Infectious hepatitis \\
\hline S.R. & $\mathrm{M}$ & 27 & 59 & 1.75 & 2.0 & 18 & Serum hepatitis \\
\hline W.M. & $\mathbf{M}$ & 65 & 58 & 1.80 & 2.2 & 14 & Serum hepatitis \\
\hline T.J. & $\mathrm{F}$ & 53 & 82 & 1.80 & 1.8 & 13 & Cholangiolitic hepatitis \\
\hline B.M. & & 27 & 62 & 1.63 & 1.8 & 11 & Cholangiolitic hepatitis \\
\hline C.N. & $\mathrm{F}$ & 28 & 57 & 1.57 & 2.4 & 8 & Acute fatty infiltration \\
\hline L.U. & $\mathrm{F}$ & 46 & 43 & 1.45 & 1.7 & 8 & Chronic common duct stricture \\
\hline N.F. & M & 51 & 53 & 1.63 & 2.0 & 2 & $\begin{array}{l}\text { Obstructive jaundice, carcinoma } \\
\text { of pancreas }\end{array}$ \\
\hline S.S. & $\mathrm{F}$ & 44 & 58 & 1.62 & 1.1 & 14 & Obstructive jaundice, choledo- \\
\hline A.J. & M & 58 & 81 & 1.88 & 3.4 & 14 & $\begin{array}{l}6 \text { Days after cholecystectomy and } \\
\text { choledocholithotomy }\end{array}$ \\
\hline F.S & $\mathrm{F}$ & 48 & 66 & 1.64 & 2.5 & 35 & Chlorpromazine jaundice, subsiding \\
\hline M.O. & $\mathbf{M}$ & 41 & 62 & 1.73 & 1.9 & 19 & Chlorpromazine jaundice \\
\hline J.L. & $\mathbf{M}$ & 41 & 72 & 1.90 & 0.6 & 48 & Dubin-Johnson syndrome \\
\hline D.D. & $M$ & 28 & 66 & 1.71 & $(-0.9)$ & 56 & Dubin-Johnson syndrome \\
\hline M.R. & $\mathrm{F}$ & 43 & 43 & 1.36 & 0.3 & 47 & Dubin-Johnson syndrome \\
\hline
\end{tabular}

* Surface area estimated from height and weight by nomogram of Boothby and Sandiford (32).

\section{Liver disease}

Patients were selected who had either primarily hepatocellular disease (hepatitis, acute fatty infiltration) or primarily obstructive disease (extrahepatic obstruction, chlorpromazine jaundice) on the theory that there might be a greater depression of $\mathrm{S}$ in the former and a greater depression of $\mathrm{Tm}$ in the latter group. However, as shown in Table III and in Figure 5 both Tm and S were reduced to approximately the same extent in patients with hepatocellular and obstructive disease. The only exception was F.S., a patient with chlorpromazine jaundice entering a period of rapid recovery at the time of the study, whose storage capacity fell within the normal range. It should be noted that all the patients with obstructive jaundice had developed symptoms at least one week before the study.

Three patients with Dubin-Johnson syndrome (chronic idiopathic jaundice) were studied, all of whom had the characteristic features of this disorder (20). In each instance the diagnosis had been established by hepatic biopsy which revealed typical centrolobular pigmentation. $\mathrm{Pa}$ tient D.D. was the nephew of M.R. ${ }^{1}$ As shown in Table III and in Figure 5 the $\mathrm{Tm}$ in these pa-

$1 \mathrm{We}$ are indebted to Drs. Irwin M. Arias and Irving M. London of the Albert Einstein College of Medicine for providing us with the opportunity to study Patients D.D. and M.R. tients was virtually zero whereas the storage capacity was well within the range established for normal subjects. In Patient J.L. the plasma BSP concentration was followed for 24 hours after termination of the actual study. During the first 8 hours it diminished from 19.1 to $13.6 \mathrm{mg}$ per 100 $\mathrm{ml}$. At the end of 16 hours the plasma level was still elevated $(9.4 \mathrm{mg}$ per $100 \mathrm{ml})$ indicating an extremely slow excretion of dye.

\section{Toxicity}

In six studies of the dog, the rapid infusion of BSP during the fourth hour increased the total administered dose to approximately 1,500 to $1,800 \mathrm{mg}$ compared to the 800 to $1,000 \mathrm{mg}$ given in the course of the usual 3 hour procedure. In three of these, toward the end of the fourth hour, there was a sharp diminution in bile flow and BSP excretion rate. All three appeared well when the study was terminated but began vomiting about 4 hours later. In one, whose bile was still being drained by way of the common duct catheter, the vomiting subsided within an hour and the dog was entirely well thereafter. The other two, in whom the catheter had been removed and the fistula closed, died within 6 hours of the onset of symptoms. Postmortem examination revealed severe gastrointestinal hemorrhage, most marked in the proximal small intestine. Microscopic examination of the liver in one revealed extensive 
acute central necrosis. With the possible exception of the gradual diminution in BSP excretory rate noted previously, no evidence of toxicity was ever observed in animals that received only the three BSP infusions involved in the basic procedure.

Among the patients studied, D.D. and M.R. noted transient nausea and vomiting following a meal which they ate together 8 hours after the study. Although the total amount of BSP infused in these two patients was not excessive $(1,520$ and $1,550 \mathrm{mg})$, the maximal plasma concentrations achieved (14.2 and $18.8 \mathrm{mg}$ per 100 $\mathrm{ml}$ ) were higher than in most other studies in man. No symptoms suggestive of toxicity were observed in any other subjects although quantities of BSP as great as $3,275 \mathrm{mg}$ were infused in normal males. While the evidence for toxicity is certainly inconclusive it seems wise to adhere to the practice of "scouting" the BSP concentration in the early blood samples so that, if necessary, the subsequent infusion rates can be altered to avoid excessively high plasma levels. More prolonged or more rapid BSP infusions than those employed here should probably be avoided.

\section{DISCUSSION}

BSP secretory transport. The foregoing observations provide direct evidence in the dog that the biliary secretion of BSP involves a rate-limited process. The maximal excretory rate was achieved when the plasma BSP concentration exceeded approximately $3 \mathrm{mg}$ per $100 \mathrm{ml}$, and further elevation of plasma concentration to as high as $48 \mathrm{mg}$ per $100 \mathrm{ml}$ did not result in any further increase in the rate of BSP excretion. Assuming a comparatively constant hepatic blood flow, this represents at least a 16-fold range in the quantity of BSP presented to the liver per unit time. In view of the variation in biliary $\mathrm{BSP}$ concentration encountered in these dogs, the limiting factor in BSP transport does not appear to be a fixed biliary concentration maximum as suggested by the studies of Brauer and Pessotti for anesthetized animals (3).

Although it has been shown that a major proportion of BSP appears in the bile in the form of chromotographically distinct conjugates (21-24), it is apparent that conjugation is not essential for
BSP secretion since a considerable amount of unconjugated $\mathrm{BSP}$ is also found in all species. However, in view of the constant ratio between the amount of BSP and its conjugates, which was observed during concurrent studies (22), one cannot be certain whether the BSP Tm refers to a single transport mechanism or to the sum of separate transport mechanisms for BSP and each of its conjugates.

The magnitude of the average estimated $\mathrm{Tm}$ in dogs $(1.9 \mathrm{mg}$ per minute per $10 \mathrm{~kg}$ ) is consistent with previous observations in this laboratory $(9$, 10 ), but is considerably lower than the $\mathrm{L}_{m}$ of $4.4 \mathrm{mg}$ per minute per $10 \mathrm{~kg}$ estimated by Mason, Hawley and Smith (11). A possible explanation for this difference is that Mason and co-workers employed a correction for variation in plasma concentration which did not take the storage phenomenon into account. If the $\mathrm{L}_{\mathrm{m}}$ was calculated during a period of increasing concentration (as it was in the one illustration presented by these authors), this could have led to a considerable overestimation of secretory function.

The degree of variation in the $\mathrm{Tm}$ from time to time in a given animal (Table I) suggests a comparable degree of variability in the biological factors which determine transport maximum. While methodological factors may have contributed to this variation, it is obvious that one must exercise caution in equating the secretory transport maximum simply to liver mass.

The finding that measured output in the bile was equal, on the average, to 87.5 per cent of the estimated $\mathrm{Tm}$ indicates that biliary secretion must be the major mechanism for continuous elimination of BSP despite the fact that some extrahepatic removal is known to occur $(10,25)$. Since the BSP conjugates in bile may have a lower molar extinction coefficient than BSP itself $(21,25)$, it is possible that the true biliary excretory rate of BSP was, if anything, underestimated by the spectrophotometric technique employed in the present studies. There is no satisfactory explanation for the gradual diminution in the BSP excretory rate noted in some of the studies on dogs. This may have been due to a toxic effect of the dye itself, to the depletion of some substrate essential for BSP transport, or to the depletion (by total bile collection) of substances such as bile salts which normally undergo entero- 
hepatic circulation and which are involved in normal bile production (26). Any change in the actual BSP secretory rate must of course affect the calculation of $\mathrm{Tm}$ and $\mathrm{S}$, which is based on the assumption of a 3 hour steady state with respect to BSP transport and storage. If the entire procedure could be shortened, the effect of this phenomenon, when it does occur, would be minimized. However, in the course of exploratory studies it became apparent that one cannot be sure of the establishment of a constant hepatic BSP removal rate within less than 30 minutes of the institution of a given rate of infusion. Thereafter, an additional 30 minutes is required for the reliable estimation of $\Delta \mathrm{p} / \Delta \mathrm{t}$ and $\mathrm{R}$. Thus it appeared unwise to allow less than 1 hour for each infusion period. The magnitude of the error caused by a diminishing BSP Tm can be estimated by substituting three appropriate hypothetical sets of values for $R, T m$ and $S$ into Equation 1 and obtaining the corresponding values for $\Delta p / \Delta t$. When the three sets of values for $\mathrm{R}$ and $\Delta \mathrm{p} / \Delta \mathrm{t}$ thus obtained were treated in the same manner as experimental data in estimating $\mathrm{Tm}$ and $\mathrm{S}$, it was found that a 15 per cent diminution in BSP Tm over the course of 3 hours would lead to a 10 per cent underestimation of the initial transport maximum. The value of $S$ would be overestimated by 6 per cent. These errors are not excessive, but data gathered over periods longer than 3 hours might well prove unreliable.

In man, the existence of a rate-limited BSP transport mechanism is indicated by the achievement of a state in which hepatic removal rate is independent of absolute plasma concentration and related only to the rate of change of plasma concentration. The mean $\mathrm{Tm}$ in normal subjects (8.6 $\pm \mathrm{SD} 1.9 \mathrm{mg}$ per minute) is considerably lower than the maximal secretory rate of $18.3 \mathrm{mg}$ per minute estimated previously by Verschure (15). The latter figure was calculated by application of the formula of Mason, Hawley and Smith (11) to data obtained during a single BSP infusion at approximately $25 \mathrm{mg}$ per minute. The actual data published by Verschure are, in fact, quite comparable to those observed during the rapid initial infusion employed in the method presented here. However, as shown in Figure 3, the hepatic BSP removal rate is regularly very high under these circumstances due to the rapid accumulation of BSP in storage, so that this removal rate cannot be equated simply to the rate of secretion. In earlier work with BSP, Bradley, Ingelfinger, Bradley and Curry (14) found that an infusion rate of approximately $3 \mathrm{mg}$ per minute per $\mathrm{m}^{2}$ (or $5.2 \mathrm{mg}$ per minute per $1.73 \mathrm{~m}^{2}$ ) was the maximal rate at which continuously rising plasma BSP concentrations could be avoided in all their normal subjects. They suggested that this might represent an approximation to the minimal normal value of BSP $\mathrm{Tm}$, and this estimate proves in fact to be roughly comparable to the lowest values of BSP $\mathrm{Tm}$ encountered in the present series (Table II).

Concentration of BSP in hepatic parenchyma. The accumulation of BSP within the hepatic parenchyma appears to proceed toward an equilibrium state in which the quantity (and hence the concentration) of "stored" material is directly proportional to the concentration of dye in the surrounding plasma. The liver behaves, in this respect, as though it were an extension of the plasma volume, and the relative storage capacity, $\mathrm{S}$, actually has the dimensions of a "volume." However, the magnitude of $\mathrm{S}$, when compared with the actual size of the liver, indicates that BSP concentration in the liver cells must be many times that in the plasma.

Assuming a liver mass of approximately $250 \mathrm{~g}$ per $10 \mathrm{~kg}$ in the $\mathrm{dog}$ and $1,500 \mathrm{~g}$ in man. the average values for $S$ of $25 \mathrm{mg}$ per $\mathrm{mg}$ per $100 \mathrm{ml}$ per $10 \mathrm{~kg}$ and $63 \mathrm{mg}$ per $\mathrm{mg}$ per $100 \mathrm{ml}$ in the two species would suggest that, with respect to plasma, the liver tends to concentrate BSP at least tenfold in the dog and fourfold in man. The range of normal values for $S$ suggests that there is considerable variation in the biological mechanisms by which this concentration ratio is maintained from one subject to another and also, at least in the dog, from time to time in a given animal. This variation is greater than that observed in the $\mathrm{Tm}$.

A high concentration ratio between liver and plasma might imply that some constituent of the liver cell has an affinity for BSP relatively greater than that of plasma protein. This would account for an ultimate relationship between liver and plasma concentrations but would certainly not explain the rapidity with which BSP, and other strongly protein-bound dyes such as rose bengal 
(27) and indocyanine green (28), actually move across the liver cell membrane. More detailed understanding of the storage phenomenon must also take into account the possible role of BSP conjugation, since alteration of chemical structure might favor the accumulation of larger amounts of dye in the liver. However, as in the case of biliary secretion, there is no evidence at present to indicate whether or not conjugation plays an essential role in the storage process.

Relationship between storage and transport. In view of the anatomical relationship between the sinusoids, the liver cells, and the bile canaliculi, it might be postulated that plasma BSP is first taken up and stored in high concentration in liver cells from which it is then transported into the biliary tract (where it reaches even higher concentrations). However, it is also possible that there is a direct route of transport between plasma and bile and that the stored BSP is a more or less separate pool in equilibrium with the plasma. The latter possibility seems less likely when the observations with sodium dehydrocholate are considered. It was shown by Cantarow and Wirts (29) that the biliary excretion of BSP is markedly retarded when sodium dehydrocholate and BSP are administered simultaneously. In the present studies, by contrast, dehydrocholate was administered only after a large amount of BSP was already stored in the liver, and there was no reduction in BSP excretion. Thus, when hepatic removal of BSP from the plasma is partially blocked by dehydrocholate it becomes apparent that the dye can be secreted directly from hepatic parenchymal storage. Although the biliary secretion of BSP may depend upon the prior storage of dye within the liver cells, it is also obvious from the studies on patients with Dubin-Johnson syndrome that secretory transport can be markedly depressed even in the presence of an entirely normal storage capacity.

BSP Tm and $S$ in liver disease. While a depression of BSP Tm was anticipated in all types of hepatic disease, a more nearly normal storage capacity might have been expected in the patients with biliary obstruction. It is not clear whether the reduced storage capacity in these patients is an indication of secondary parenchymal damage or whether it is due to the retention of specific substances which interfere with BSP storage.
However, it is obvious that measurements of $\mathrm{Tm}$ and $\mathrm{S}$ could not be used clinically to distinguish between obstructive and hepatocellular jaundice.

Extrahepatic removal of BSP, which can be practically disregarded when hepatic function is normal $(10,30)$, should not be increased in patients with hepatic disease provided the BSP infusion rates are reduced sufficiently to avoid excessively high plasma concentrations. Nevertheless, the ratio of extrahepatic to total BSP removal is necessarily greater when hepatic function is impaired and this will affect the estimation of $\mathrm{Tm}$ or $\mathrm{S}$ or both (depending upon the behavior of the extrahepatic mechanisms). Hence the reduction in $\mathrm{Tm}$ and $\mathrm{S}$ in patients with liver disease must have been, if anything, even more marked than the values in Table III and in Figure 5 would indicate.

It is noteworthy that the estimated values of Tm exceeded $1 \mathrm{mg}$ per minute in all pateints with total biliary obstruction. While this may be explained in part by extrahepatic BSP removal, it is difficult to reconcile this explanation with the consistently lower $\mathrm{Tm}$ values observed in patients with Dubin-Johnson syndrome (whose extrahepatic removal should be just as great). The possibility that there is some secretion of BSP into the obstructed biliary tree cannot be excluded.

The findings in patients with Dubin-Johnson syndrome support the prevailing concept (20) that this disorder involves a specific excretory defect without significant disturbance of other hepatocellular functions. The values of $\mathrm{Tm}$ and $\mathrm{S}$ observed in this syndrome would lead one to anticipate a sharp break in the BSP disappearance curve and a markedly reduced quantity of $\mathrm{BSP}$ in the bile as noted by Mandema, de Fraiture, Nieweg and Arends (31) following a single BSP injection. However, the regularly demonstrable relationship between hepatic BSP storage and plasma BSP concentration is inconsistent with the viewpoint, proposed by these authors, that hepatic storage capacity can be defined by an absolute maximal value. Patients with Dubin-Johnson syndrome, like normal subjects, appear to store BSP in the hepatic parenchyma in high concentration relative to plasma. In contrast to normal subjects, however, they are practically incapable of transporting BSP into the biliary tract. 


\section{SUMMARY}

The rate of removal $(R)$ of sulfobromophthalein sodium (BSP) from the blood is a function of 1 ) the rate of secretion of dye into the bile and 2) the rate of accumulation (or depletion) of dye in the hepatic parenchyma. BSP transport into the bile is a rate-limited process which becomes constant $(\mathrm{Tm})$ when the plasma concentration of BSP is in excess of $3 \mathrm{mg}$ per $100 \mathrm{ml}$. The accumulation of BSP in the hepatic parenchyma appears to proceed toward an equilibrium state in which the quantity of "stored" dye is proportional to BSP concentration in the surrounding plasma.

Extrahepatic tissue uptake is relatively small and may be considered negligible in defining BSP removal $(R)$ in terms of active transport and storage as follows: $R=T m+S \cdot(\Delta p / \Delta t)$, where $\Delta \mathrm{p} / \Delta \mathrm{t}$ is the change in plasma BSP concentration in milligrams per $100 \mathrm{ml}$ per minute and $\mathrm{S}$ is the number of milligrams stored per milligram per $100 \mathrm{ml}$ of plasma BSP concentration. The quantity " $\mathrm{S}$ " has been designated as the "relative storage capacity." The two unknowns, Tm and $\mathrm{S}$, may be determined by the solution of simultaneous equations from values for $R$ and $\Delta p / \Delta t$ obtained from the slopes of the plasma BSP concentration curves at different constant rates of BSP infusion.

Since $\mathrm{S}$, which has the dimensions of volume, has proved to be several times larger than the volume of the liver itself, it may be inferred that $\mathrm{BSP}$ is concentrated in the liver cells.. The linear correlation between $\mathrm{R}$ and $\Delta \mathrm{p} / \Delta \mathrm{t}$ at various infusion rates in the normal dogs or human subjects is consistent with constancy of both $\mathrm{Tm}$ and $\mathrm{S}$ within the range of BSP concentrations explored.

In six dogs, BSP Tm averaged $1.9 \mathrm{mg}$ per minute per $10 \mathrm{~kg}$ body weight, and $\mathrm{S}$ was $25 \mathrm{mg}$ per $\mathrm{mg}$ per $100 \mathrm{ml}$ per $10 \mathrm{~kg}$ body weight. The maximal rate of biliary BSP excretion (measured colorimetrically) in the dog proved to be $87.5 \pm$ SD 13.4 per cent of the value for Tm.

Direct transport of BSP from hepatic parenchymal storage into bile was demonstrated by the fact that excretory rate was maintained at a time when hepatic uptake from plasma was inhibited by sodium dehydrocholate (two dogs).

In 19 normal human subjects Tm was $8.6 \pm$ $\mathrm{SD} 1.9 \mathrm{mg}$ per minute, and $\mathrm{S}$ was $63 \pm \mathrm{SD} 25$ mg per mg per $100 \mathrm{ml}$. Both values were diminished in patients with obstructive or hepatocellular jaundice. In three patients with Dubin-Johnson syndrome the value for Tm approached zero while the relative storage capacity was entirely normal.

\section{ACKNOWLEDGMENT}

The authors are indebted to Miss Evelyn Audioun, Mrs. Susan Stassa and Mrs. Ann Steele for their valuable technical assistance.

\section{REFERENCES}

1. Rosenthal, S. M., and White, E. C. Studies in hepatic function. VI. A. The pharmacological behavior of certain phthalein dyes. B. The value of selected pththalein compounds in the estimation of hepatic function. J. Pharmacol. exp. Ther. 1924, 24, 265.

2. Wirts, C. W., Jr., and Cantarow, A. A study of the excretion of bromsulphthalein in the bile. Amer. J. dig. Dis. 1942, 9, 101.

3. Brauer, R. W., and Pessotti, R. L. Hepatic uptake and biliary excretion of Bromsulphthalein in the dog. Amer. J. Physiol. 1950, 162, 565.

4. Mendeloff, A. I., Kramer, P., Ingelfinger, F. J., and Bradley, S. E. Studies with bromsulfalein: II. Factors altering its disappearance from the blood after a single intravenous injection. Gastroenterology 1949, 13, 222.

5. Graffin, A. L., and Bagley, E. H. Studies of hepatic structure and function by fluorescence microscopy. Johns Hopk. Hosp. Bull. 1952, 90, 395.

6. Hanzon, V. Liver cell secretion under normal and pathologic conditions studied by fluorescence microscopy on living rats. Acta physiol. scand. 1952, 28, suppl. 101.

7. Taplin, G. V., Meredith, O. M., Jr., and Kade, H. The radioactive ( $\mathrm{I}^{131}$-tagged) rose bengal uptakeexcretion test for liver function using external gamma-ray scintillation counting techniques. J. Lab. clin. Med. 1955, 45, 665.

8. Glaser, W., Gibbs, W. D., and Andrews, G. A. The mechanism of removal of rose bengal from the plasma of the rat. J. Lab. clin. Med. 1959, 54, 556.

9. Combes, B., Wheeler, H. O., Childs, A. W., and Bradley, S. E. The mechanisms of Bromsulfalein removal from the blood. Trans. Ass. Amer. Phycns 1956, 69, 276.

10. Wheeler, H. O., Epstein, R. M., Robinson, R. R., and Snell, E. S. Hepatic storage and excretion of sulfobromophthalein sodium in the dog. J. clin. Invest. 1960, 39, 236.

11. Mason, M. F., Hawley, G., and Smith, A. Application of the saturation principle to the estimation of functional hepatic mass in normal dogs. Amer. J. Physiol. 1948, 152, 42. 
12. Lewis, A. E. Investigation of hepatic function by clearance techniques. Amer. J. Physiol. 1950, 163, 54.

13. Taleisnik, S. Liver mass determination by bromsulphalein in partially hepatectomized rabbits. Gastroenterology 1955, 29, 64.

14. Bradley, S. E., Ingelfinger, F. J., Bradley, G. P., and Curry, J. J. The estimation of hepatic blood flow in man. J. clin. Invest. 1945, 24, 890.

15. Verschure, J. C. M. Clinical use of measurements of clearance and maximum capacity of the liver. Acta med. scand. 1952, 142, 409.

16. Croxton, F. E., and Cowden, D. J. Applied General Statistics. New York, Prentice-Hall, 1946, p. 399.

17. Thomas, J. E. An improved cannula for gastric and intestinal fistulas. Proc. Soc. exp. Biol. (N. Y.) 1941, 46, 260.

18. Cantarow, A., Wirts, C. W., Snape, W. J., and Miller, L. L. Excretion of bilirubin and Bromsulfalein in bile. Amer. J. Physiol. 1948, 154, 211.

19. Lorber, S. H., Oppenheimer, M. J., Shay, H., Lynch, P. and Siplet, H. Enterohepatic circulation of bromsulphalein: Intraduodenal, intraportal, and intravenous dye administration in dogs. Amer. J. Physiol. 1953, 173, 259.

20. Dubin, I. N. Chronic idiopathic jaundice. A review of fifty cases. Amer. J. Med. 1958, 24, 268.

21. Krebs, J. S., and Brauer, R. W. Metabolism of sulfobromophthalein (BSP) in the rat. Amer. J. Physiol. 1958, 194, 37.

22. Meltzer, J. I., Wheeler, H. O., and Cranston, W. I. Metabolism of sulfobromophthalein sodium (BSP) in dog and man. Proc. Soc. exp. Biol. (N. Y.) 1959, 100, 174.

23. Combes, B. The biliary excretion of sulfobromophthalein sodium (BSP) in the rat as a conjugate of glycine and glutamic acid. J. clin. Invest. 1959, 38, 1426.

24. Grodsky, G. M., Carbone, J. V., and Fanska, R. Identification of metabolites of sulfobromophthalein. J. clin. Invest. 1959, 38, 1981.

25. Brauer, R. W., Pessotti, R. L., and Krebs, J. S. The distribution and excretion of $\mathrm{S}^{35}$-labeled sulfobromophthalein-sodium administered to dogs by continuous infusion. J. clin. Invest. 1955, 34, 35.

26. Wheeler, H. O., and Ramos, O. L. Determinants of the flow and composition of bile in the unanesthetized dog during constant infusions of sodium taurocholate. J. clin. Invest. 1960, 39, 161.

27. Delprat, G. D., Jr. Studies on liver function. Rose bengal elimination from the blood as influenced by liver injury. Arch. intern. Med. 1923, 32, 401.

28. Wheeler, H. O., Cranston, W. I., and Meltzer, J. I. Hepatic uptake and biliary excretion of indocyanine green in the dog. Proc. Soc. exp. Biol. (N. Y.) 1958, 99, 11

29. Cantarow, A., and Wirts, C. W., Jr. The effect of dog's bile, certain bile acids and India ink on bilirubinemia and the excretion of bromsulfalein. Amer. J. dig. Dis. 1943, 10, 261.

30. Bradley, S. E., Clinical aspects of hepatic vascular physiology in Transactions of the Ninth Conference on Liver Injury. New York, Josiah Macy, Jr., Foundation, 1950, p. 71.

31. Mandema, E., de Fraiture, W. H., Nieweg, H. O., and Arends, A. Familial chronic idiopathic jaundice (Dubin-Sprinz disease), with a note on bromsulphalein metabolism in this disease. Amer. J. Med. 1960, 28, 42.

32. Boothby, W. M., and Sandiford, R. B. Nomographic charts for the calculation of metabolic rate by the gasometer method. Bost. med. surg. J. 1921, 185,337 . 